\title{
The light-weight design of tower for under typhoon wind turbine
}

\section{based on the typhoon control strategy}

\author{
Yongshui LUO ${ }^{1, a^{*}}$, Qi CHEN ${ }^{1}$, Danyuan REN ${ }^{1}$,
}

\author{
Xueping LI ${ }^{1}$, Yuanwen Liao ${ }^{1}$
}

${ }^{1}$ State Key Laboratory of Wind Power System, Zhejiang Windey Co., Ltd, Hangzhou 310012, China

aluoys@chinawindey.com

Keywords: wind power; the typhoon environmental load cases; the typhoon control strategy; tower base load; load test

Abstract. Aiming at the light-weight design of tower for under typhoon wind turbine, the typhoon environment load cases and control strategy were researched. Based on the conventional design of under typhoon wind turbine and $《 G B / T$ 31519-2015 wind turbine generator system under typhoon condition》 standard, a developed typhoon control strategy was proposed to protect turbine and decrease the weight of tower. In this study, the load cases of the critical structures of wind turbine were calculated through software BLADED after applying the novel control strategy, and it indicated that the tower base load could be reduced by $24 \%$ and thus the weight of the optimized tower could be lightened by $11 \%$, which saved about 348 million RMB for one wind farm. Furthermore, a field experiment was conducted, and proved that the measured load values and the simulated ones share a high consistency (namely 96.7\%), which verifies the accuracy of theoretical calculation and feasibility of light-weight tower application. In conclusion, this study provides a method to improve the design of under typhoon and offshore wind turbine design with reliable and economic benefits.

\section{Introduction}

With the rapid development of wind power industry, a great number of wind turbines have been installed in southeast coast of China. However, typhoon frequently lands on the coastal areas and causes great harm to wind farms. From 1997, a total of 23 typhoon has affected Zhejiang province, among which 8 typhoon caused more than one million RMB loss due to damage to equipments. Particularly in 2006, typhoon Saomai devastated a wind farm in Cang nan ${ }^{[1]}$ and led to tens of millions RMB loss. Since the increase of capacity of new wind turbines, especially for offshore wind turbines, once the typhoon damage occurs, the loss will be even more serious. So it is significant to improve wind turbines' ability to resist typhoon.

The research of typhoon-resistant technology of wind turbine was mainly conducted in Japan, Southeast Asia, China and other countries and regions where the typhoon lands frequently. In 2004, Japan initiated a three-year program about the under typhoon design of wind turbine ${ }^{[2-4]}$.The program mainly includes load testing, extreme wind atlas, extreme wind database, the site assessment of wind farm, the guidelines of unit selection etc.

In 2005, Denmark's national energy laboratory, uniting with Philippines, Vietnam and other ASEAN countries, launched a research project called the "EU - ASEAN wind project" [5]. By the investigation of extreme wind speed throughout Philippine, a preliminary study of the structural 
safety design requirements of wind turbine in typhoon areas was done and a proximate analysis of the increase of unit cost resulted from the increase of the safety factor was made.

The design technology of offshore wind turbine in the hurricane environment was studied by the American Bureau of Shipping under the support of the Ministry of the Interior. According to the report ${ }^{[6-7]}$, the calculation model of wind load of offshore wind turbine installed in the hurricane region was recommended as API (American Petroleum Institute) standard model.

At present, well-known manufacturers of wind turbines like Mitsubishi, VESTAS and GE all carry on the study of wind turbine generator system under typhoon condition. They focus on the research of extreme wind speed/extreme wind load and their harm, and the optimization and improvement of the structure and control strategy by using the existing conditions of the unit ${ }^{[8-12]}$.

Benefiting from China - EU energy and environmental cooperation project "Study on the impact of Typhoon on the offshore wind power development" and absorbing the experience from domestic wind farms' typhoon accidents ${ }^{[13-15]}$, China carried out a systematic analysis and study on the situation of typhoon landing in coastal waters of China, the extreme wind velocity distribution and the damage mechanism of the typhoon ${ }^{[16]}$. In the project, Chinese first standard specification for wind turbine under typhoon condition $《 G \mathrm{~GB} / \mathrm{T}$ 31519-2015 wind turbine generator system under typhoon condition》 was proposed ${ }^{[17]}$. Based on the standard, this paper developed the typhoon control strategy, optimized the structural design of the tower through load calculation and realized the lightweight design of the tower with a substantial economic benefit. Through the field load test, the accuracy and feasibility of the theoretical design was verified, helping the development of wind power industry in China's coastal areas and offshore wind turbine.

\section{Design of wind turbine under typhoon condition}

The research object

A coastal wind field in Ninghai of Zhejiang Province was selected as the research object, which uses WD103-2000 typhoon unit. The basic parameters of the unit are shown in Table 1.

Table 1: Basic parameters of WD103-2000 under typhoon wind turbine

Load calculation

\begin{tabular}{cc}
\hline Item & Parameter \\
\hline Rated power & $2000 \mathrm{~kW}$ \\
Impeller diameter & $103 \mathrm{~m}$ \\
Wheel hub height & $80 \mathrm{~m}$ \\
Rated wind speed & $9.9 \mathrm{~m} / \mathrm{s}$ \\
Vin to Vout & 3 to $25 \mathrm{~m} / \mathrm{s}$ \\
Air density & $1.225 \mathrm{~kg} / \mathrm{m}^{3}$ \\
Characteristic turbulence & $16 \%$ \\
intensity I15 & $37.5 \mathrm{~m} / \mathrm{s}$ \\
$\mathrm{V}_{50}$ & $52.5 \mathrm{~m} / \mathrm{s}$ \\
$\mathrm{V}_{\text {e50 }}$ & $8 \mathrm{~m} / \mathrm{s}$ \\
$\mathrm{V}_{\text {ave }}$ &
\end{tabular}

The typhoon load cases dlc1.1 dlc9.14 are combined load cases dlc1.1 dlc8.2 according to the standard 《GB/T 18451.12012 wind turbine design requirements》 with typhoon load cases specified in the standard 《GB/T 31519-2015 wind turbine generator system under typhoon condition》.

Loads of main structures, such as blade root, wheel hub, the top of the tower, the base of the tower, were calculated by software BLADED, and the results are shown in Table 2. 
Structural design and strength calculation of each component have been done according to the load calculation results shown in Table 2. This paper concentrates on tower design, and it turns that the tower, which is designed according to the load of the base of the tower and each cross section, only weighs about 199 tons.

Table 2: The load calculation results of under typhoon wind turbine

\begin{tabular}{cccccc}
\hline $\begin{array}{c}\text { Load } \\
\text { coordinate }\end{array}$ & Direction & Parameter & $\begin{array}{c}\text { Load } \\
\text { coordinate }\end{array}$ & Direction & Parameter \\
\hline \multirow{6}{*}{ B-Root } & Mxy & 8962.7 & & Mxy & 97685 \\
& Mz & 208.2 & T-base & Mz & 6172 \\
& Fxy & 455.1 & & Fxy & 1451.3 \\
& Fz & 1145.3 & & Fz & 4741.4 \\
& Mx & 3283.8 & & Mxy & 9053.9 \\
R-Hub & Myz & 7825.1 & Ttop & Mz & 6169 \\
& Fx & 717.09 & & Fxy & 933 \\
& Fyz & 944.2 & & Fz & 2070 \\
& Mx & 3283.8 & & & \\
S-Hub & Myz & 7825.1 & & & \\
& Fx & 717.09 & & & \\
& Fyz & 944.2 & & & \\
\hline
\end{tabular}

\section{The design of the typhoon control strategy}

The design of the typhoon control strategy

The Tower-base's load of under typhoon wind turbine was analyzed and it is found that the limit load occurs in the load case dlc9.10. When the wind direction is 0 degree or 180 degree, namely unit is in the windward or leeward direction, the load is the minimum and the value is only about $50 \%$ of the maximum value, as shown in Figure 1. If units can continue to align the wind direction during typhoon, the loading of tower beard will decline sharply, thus the light-weight design of the tower can be realized. Based on this idea, the typhoon control strategy was designed and developed, as shown in Figure 2.

The typhoon control strategy system is mainly composed of four major components as following:

The development of SCADA

SCADA undertakes four different tasks of the yaw standby system, respectively (1) the typhoon warning function, (2) typhoon transited prompt facility, (3) remote control of all the wind turbines to enter the yaw standby mode and (4) remote turn-on of the power supply standby system when the power grid is lost in the typhoon.

48 hours before the arrival of the typhoon, a typhoon warning is made according to the meteorological information system. When the typhoon arrived in 24 hours, the units check the status of wind power grids, communications networks, diesel generator and personal in place to ensure that the unit can enter the typhoon yaw standby mode at any time. When the typhoon hits, the units enter the yaw standby mode once the wind speed is greater than the set value (cut-out speed). After the typhoon passes and the wind speed is less than set value (cut-out speed), self-inspection of wind field should be conducted, including the self-inspection of unit, the power line, communication network and auxiliaries. The fault, if exists, will be solved to make the unit resume operation.

Optimal control of unit 
The purpose is to realize the following functions: when the wind turbines operate in the yaw standby mode, early warning and alarm signal for the automatic yaw of the unit is shielded and stopped, to ensure that these signals have nothing to do with personal safety and the safety of the unit. Before the self-inspection of wind field is finished, it should make sure that the unit can't enter the normal operation mode automatically, even if the instructions are sent by SCADA operator to make the unit enter the normal operation mode.
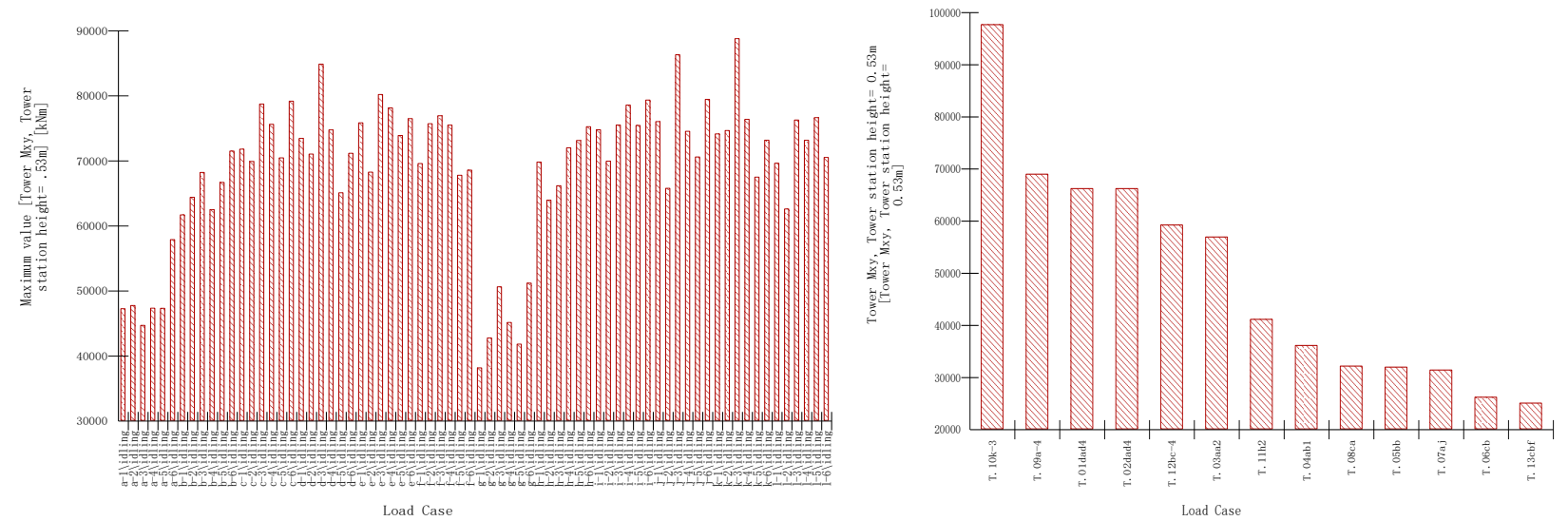

Fig.1. The Tower base's load in different wind angles Fig.3. The Tower base's load diagram under typhoon load cases under the load case DLC9.10

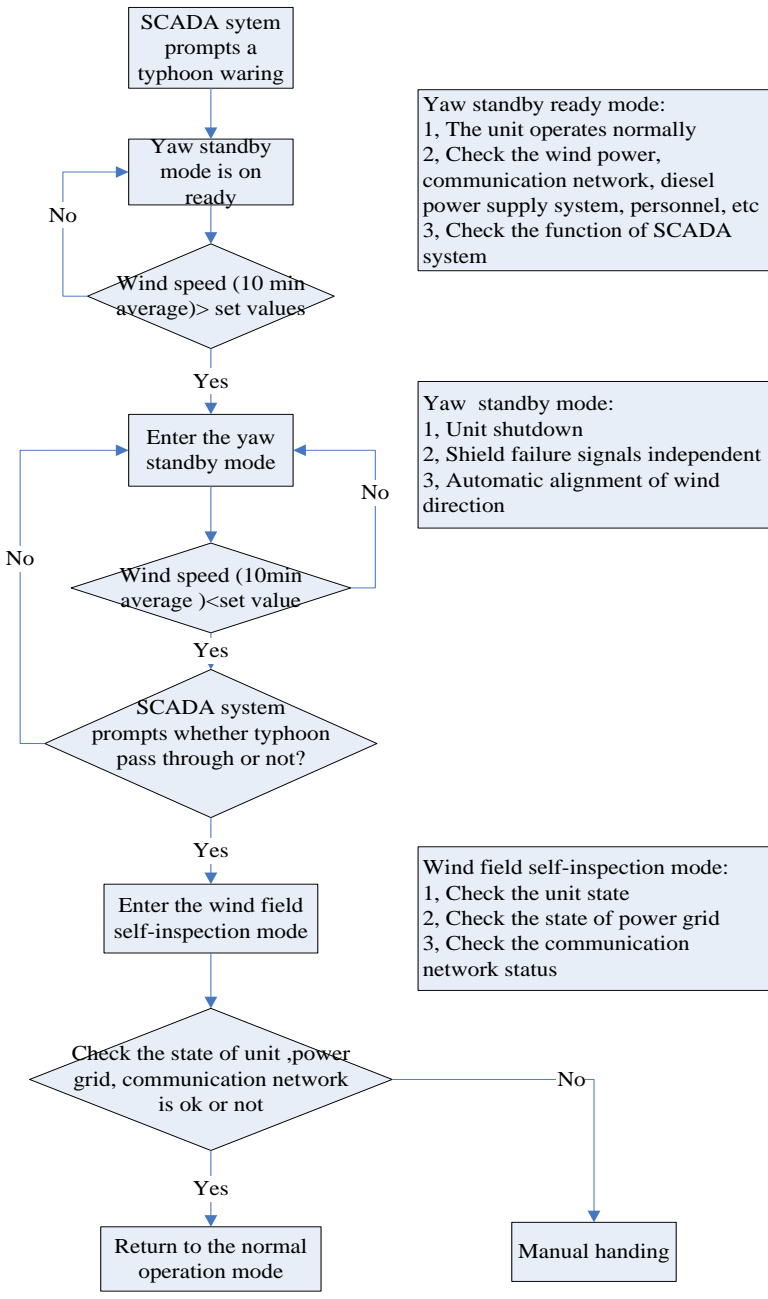

Fig.2. The flow chart of the typhoon control strategy

The power supply standby system

The standby system of the power supply adopts the plan of centralized power supply, which ensures 
that when the power grid is lost, the unit will be able to continue to yaw. The standby system of the power supply adopts a set of diesel generator system to supply power to the whole wind farm, the capacity of the system need to consider the numbers of Collection Lines in wind farm like voltage level, the circuit topology, number of circuits, type and size of lines, etc. Besides, the unit type and quantity as well as the diesel generator's power factor also need to be considered.

The anemorumbometer

At present, the maximum wind speed that the anemorumbometer is able to measure is only $50 \mathrm{~m} / \mathrm{s}$. During typhoon, the wind speed and wind direction change fast, and the wind information is needed even when the speed is close to $70 \mathrm{~m} / \mathrm{s}$. Therefore, it is necessary to choose a suitable anemorumbometer.

Load calculation

The Tower base's load diagram of the under typhoon wind turbine designed according to 《GB/T 31519-2015 wind turbine generator system under typhoon condition》 standard is shown in Figure 3. As Figure 3 shows the limit load of $\mathbf{M}_{\mathrm{xy}}$ appears in the load case DLC9.10k-3 and the value is 97685.4kN.m. The second biggest load appeares in the load case DLC9.9a-4 and the value is $69007 \mathrm{kN} . \mathrm{m}$.

The typhoon control strategy mainly affects the typhoon load DLC9.10. When the cabin is in agreement with the wind direction, the load of tower base is about $50000 \mathrm{kN}$.m, which is far less than the maximum value and less than second biggest load whose value is $69007 \mathrm{kN} . \mathrm{m}$ in load case DLC9.9a-4. Combined with the load cases dlc1.1 dlc8.2 set on the standard 《GB/T 18451.1-2012》, the maximum value of $\mathrm{M}_{\mathrm{xy}}$ is $74259 \mathrm{kN}$.m appearing in the load case dlc1.5. Finally, a comprehensive analysis was conducted and the maximum value of $\mathrm{M}_{\mathrm{xy}}$ under the typhoon control strategy is $74259 \mathrm{kN} . \mathrm{m}$.

\section{The light-weight design of tower}

The light-weight design of tower

The result of load calculation shows that, the typhoon control strategy used in wind turbine can effectively reduce the load of tower and increase the design safety margin of tower. The $\mathrm{M}_{\mathrm{xy}}$ of Tower base's load is reduced (97685-74259) /97685=24\% after the under typhoon control strategy is adopted. According to the limit load of tower base and load distribution of each section, as shown in Figure 4, the light-weight design of tower is realized, and the redesigned tower only weighs about 177 tons.

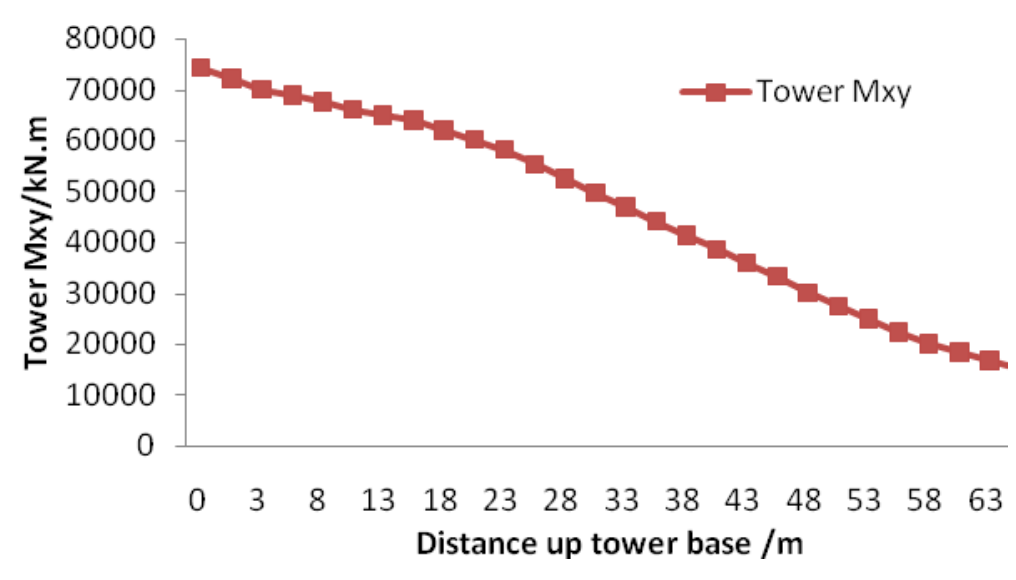

Economic benefit

Fig.4. The value of new tower's $M_{x y}$ changed with the tower height

Taking a coastal wind farm in Ninghai of Zhejiang Province as an example, the number of wind 
turbine is 24 . The tower's weight of unit with the typhoon control strategy is about 177 tons while the others' weight without the typhoon control strategy is about 199 tons. So the construction costs of towers in each wind farm can save: $(199-177)$ ton $* 24 * 8000 \mathrm{RMB} /$ ton=4.23 million RMB. Among them, 8 thousand RMB / ton is the unit price for the tower processing and transporting.

In order to be in a state of aligning wind direction during the typhoon period, the yaw system of the under typhoon wind turbine with the typhoon control strategy needs to be operated continuously. The standby power supply adopts three $200 \mathrm{~kW}$ diesel generators to ensure the continuity of the power supply. In the 20 years of the wind turbine life, the sum of acquisition costs of diesel generator, diesel consumption and the cost of line transformation, maintenance and other costs, is about 750 thousand RMB. In this case, 4.23-0.75=3.48 millions RMB is saved in total. Therefore, the design of under typhoon wind turbine based on the typhoon control strategy can not only realize the light-weight design of tower, but also has a good economic effect, which is good for investors to reduce investment cost and risk.

\section{Field load test and analysis}

Field test of 2 prototypes (A08 and A09) has been conducted in a coastal wind farm in Ninghai of Zhejiang Province. In the test, A08 is the conventional under typhoon wind turbine designed according to $《 \mathrm{~GB} / \mathrm{T} 31519-2015$ wind turbine generator system under typhoon condition》 standard, while A09 has been applied by the typhoon control strategy.

This unit load test includes the measurement of loads of blade-root, loads of hub and loads of tower. Only the tower-base load was measured since the test was conducted on the condition that the control strategy can mainly reduce the tower-base load.

Resistance strain gauge was installed 4.0 meters away from the tower flange plane to measure the bending moment of tower base. The data acquisition unit of the test is composed of 2 CANSAS IMC modules (SC16, DI16) and a CS7008 IMC host module produced by IMC Co., Ltd. The data processing system is used to analyze the data collected during the Chan-hong typhoon in July of 2015. Besides the data of two units' yaw error and the statistical data for each channel of tower-base load were obtained, combined bending moment Mxy of the tower-base was gained by doing real-time calculation of the measured data through the data channel.

The analysis of yaw error

During the typhoon Chan-hong, the maximum 10-minute average wind speed is $35 \mathrm{~m} / \mathrm{s}$ as the field test data showed. The yaw error of unit A08 is present in Figure 5: the yaw error of unit A08 is primarily in the range of -50 to +50 degrees and the maximum value is 171 degree which is a very large deviation. On the other hand, the yaw error of unit A09 is shown in Figure 6: the yaw error is in the range of -8 to +8 degrees, namely the unit was always being in a state of alignment of the wind. The comparison shows that the typhoon control strategy can help the unit to be in a state of alignment of the wind in real time, which verifies the effectiveness of the strategy. 


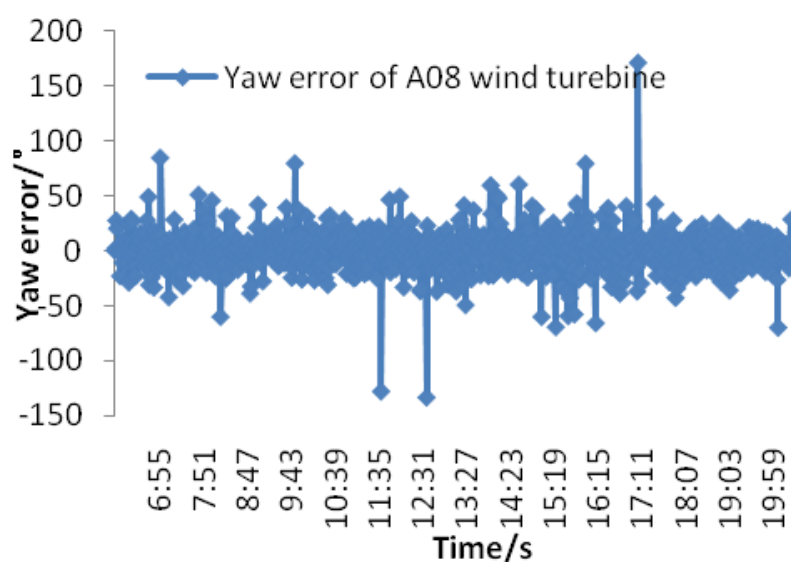

Fig.5.The yaw error of unit A08 during typhoon

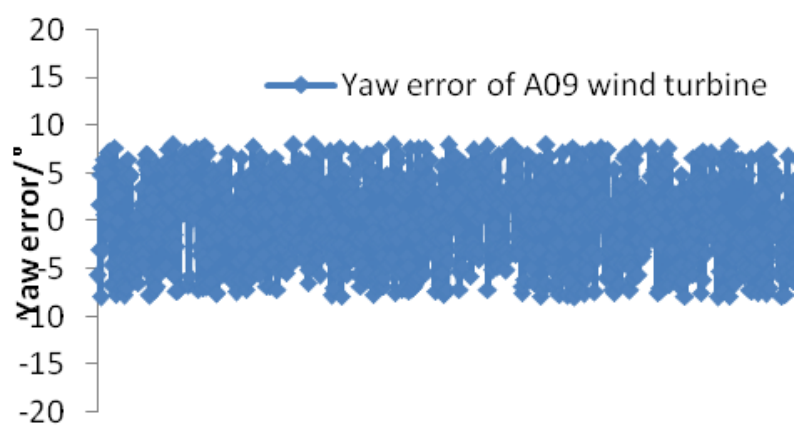

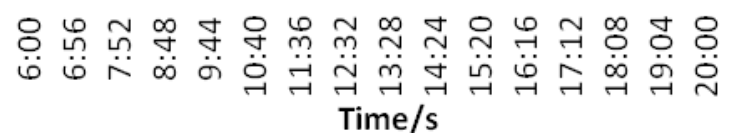

Fig.6.The yaw error of unit A09 during typhoon

The analysis of tower-base load

By comparing the tower-base load $\mathrm{M}_{\mathrm{xy}}$ of A08 and A09 during the typhoon, as shown in Figure 7, it is known the load $\mathrm{M}_{\mathrm{xy}}$ of origin under typhoon unit was $41000 \sim 51000 \mathrm{kN} . \mathrm{m}$, while the $\mathrm{M}_{\mathrm{xy}}$ 's value of the unit with the typhoon control strategy was 23000 36000kN.m. Compared with A08's load, the value of A09 reduced by $15000 \mathrm{kN}$.m, which was about $30 \%$ of the load $\mathrm{M}_{\mathrm{xy}}$ of under typhoon unit. It is confirmed that the typhoon control strategy can reduce the tower-base load effectively which is conducive to the optimal structure design of lightweight tower.

Comparative analysis of measured load and theoretical load

During the typhoon Chan-hong, the maximum 10-minute average wind speed is $35 \mathrm{~m} / \mathrm{s}$ that didn't reach the designed value of the maximum 10-minute average wind speed $42 \mathrm{~m} / \mathrm{s}$. In order to evaluate the correlation between the measured and theoretical values of the unit A09 during the typhoon period, the measured $\mathrm{M}_{\mathrm{xy}}$ values were compared with the ones calculated by BLADED software in the load case dlc9.10 (including typhoon control strategy). From the result shown in Figure 8 the measured $\mathrm{M}_{\mathrm{xy}}$ are slightly higher than the calculated, but the overall trend is a fundamental consistent. Especially in the wind speed range of $25 \sim 35 \mathrm{~m} / \mathrm{s}$, the correlation between the two is $96.7 \%$, which is highly consistent. The consistency between the theoretical simulation and the measurement is verified. It further certifies that the typhoon control strategy is effective and lightweight design of tower is feasible.

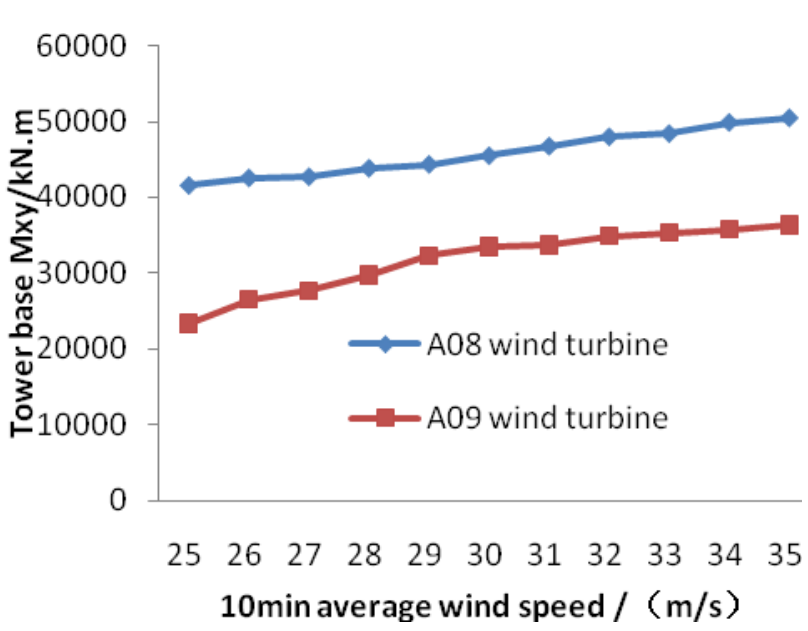

Fig.7.The statistical values of 2 units' $M_{x y}$

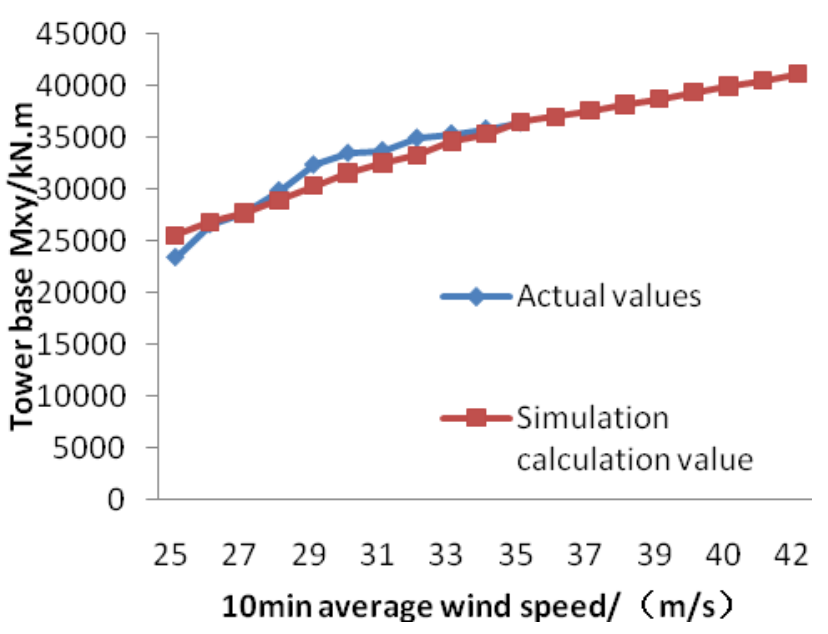

Fig.8.The comparison chart of measured value and simulation value of A09 unit's $\mathrm{M}_{\mathrm{xy}}$ 


\section{Conclusion}

This paper mainly elaborates a novel typhoon control strategy in the interest of light-weight tower design, which suits for the under typhoon wind turbine designed according to 《GB/T 31519-2015 wind turbine generator system under typhoon condition》. Through the field test carried out on two under typhoon wind turbines in a coastal wind farm in Ninghai, Zhejiang, comparative analysis of load data has been done and delivers the results as follows:

1) If the typhoon control strategy was applied, the tower base load will be reduced by $24 \%$ compared with the situation without the typhoon control strategy. Under this condition, $11 \%$ weight of the tower can be lost to realize the light-weight design of tower, saving about 3.48 millions RMB for a single wind farm and minimizing the cost and risk for investors.

2) The yaw error of unit A09 with the typhoon control strategy is in the range of -8 and +8 degrees, while the yaw error of unit A08 without the typhoon control strategy is in the range of -50 and +50 degrees. Worse still, the maximum value in A08 case is 171 degree. The comparison shows that the typhoon control strategy can help the unit keep in a state of alignment to the wind in real time.

3) The measured load of unit A09 with the typhoon control strategy and the theoretical values have a high consistency, the similarity of which is $96.7 \%$. It verifies the high accuracy of theoretical calculation and strong feasibility of the light-weight tower design

\section{References}

[1] Wang Liyu, Xu Yiqin. The damage of typhoon to wind farm and preliminary study on the the characteristics of typhoon [J]. Wind Energy, 2012(5): 74-79. (in Chinese)

[2] Takeshi Ishihara, Atsushi Yamaguchi, Keiji Takahara, et al. Ananalysis of damaged wind turbines by typhoon Maemi in 2003 [A]. Proceedings of the Sixth Asia-Pacific Conference on Wind Engineering (APCWE-VI): The Sixth Asia-Pacific Conference on Wind engineering [C], Seoul, Korea, 2005 (6): 1413-1428.

[3] Matsumiya H, Takada K, Matsushita D, et al. J-Class wind characteristics-A study on extreme wind speed in tropical region [A]. Proceedings of the European Wind Energy Conference \&Exhibition 2007 [C], Milan, Italy, 2007: 637-645.

[4] Kogaki T, Matsumiya $\mathrm{H}$, Abe $\mathrm{H}$, et al. Wind characteristics and wind models for wind turbine design in Japan [J]. Journal of Environment and Engineering, 2009, 4(3): 467-478.

[5] Tarp-Johansen N J, Clausen N E. Design of wind turbines in typhoon area: A first study of structural safety of wind turbines in typhoon prone areas [R]. Denmark: EC-ASEAN Energy Faciltiy, 2006.

[6] ABS. Guide for building and classing offshore wind turbine installations [S]. USA: American Bureau of Shipping, 2010.

[7] ABS. Design standards for offshore wind farms [R]. USA:Bureau of Ocean Energy Management, Regulation, and Enforcement, 2011.

[8] Fujikawa. Mitsubishi high efficiency large capacity wind turbines [J]. Mitsubishi Heavy Industries Technical Review, 2002, 39(3).

[9] Ueda Y. Recent trends about wind turbine generator system [J]. The Thermal and Nuclear Power, $2002,8$.

[10] Itaka.H, Ueda.Y. The first $2000 \mathrm{~kW}$ wind turbine in Japan [J]. Eco Industry, 2003, 7.

[11] BTM Consults Aps. International wind energy department-world market update 2002 [R]. 2003. 
[12] Martin E.Batts, LarryR.Rusell. Hurricane wind speeds in the United States [J]. Journal of the Structural Division, 1980 and Gulf coasts of the United States, Coastal Zone Information Center, 1970.

[13] Yan Shengbiao. The harm and countermeasures of typhoon to wind farm [J]. Energy and Environment, 2012,31(4): 43-44. (in Chinese)

[14] Yu Wuming. Harm and thought of typhoon "Dujuan" brought [A]. Chinese Society For Electrical Engineering [C], Beijing, 2004. (in Chinese)

[15] Wu Jincheng. The influence and enlightenment of Typhoon "Saomai" [J]. Wind Energy, 2008, 2(2): 11-18. (in Chinese)

[16] Wu Jincheng, Zhang Rongyan, Zhang Xiuzhi. Anti typhoon design of offshore wind turbine [J]. Engineering Sciences, 2010, 12(11): 25-31. (in Chinese)

[17] GB/T 31519-2015, wind turbine generator system under typhoon condition [S]. (in Chinese) 